\title{
Managing Leader Identity at Work: A Practice-Oriented Approach
}

\author{
Charles D. Kerns \\ Pepperdine University \\ Corperformance, Inc.
}

It is important for leaders to have a clear, credible and motivating view of who they are and who they want to become as a leader. Understanding and managing leader identity is a key practice area for leaders. After reviewing some relevant literature, a practice-oriented framework is offered which focuses on some key elements of leader identity and is operationalized through a management cycle. A review of the application value, implications and challenges of this approach is provided. With increasing accountability for organizational outcomes including stakeholder performance, well-being and well-doing, this approach offers practitioners a way to understand and manage key considerations relating to managing leader identity at work for positive impact.

Keywords: leader identity, self-views, strategic questioning, identity factors, narrative, story, strengthimpact matrix, performance, well-being, well-doing

\section{INTRODUCTION}

Managing leader identity is a multifaceted process which spans a broad array of topics and related subject areas, many of which hold practical utility for advancing the study and application of this practice in organizational settings. This article provides a practitioner perspective on how to manage leader identity at work drawing from my own work as well as from a multitude of conceptual and empirical evidence surrounding the study of identities. This practice-oriented perspective connects with Brown's recent review of identity related theories/research and to his call for additional scholarship which cuts across identity related topics to stimulate critical reflection relating to studying identities in organizational settings (Brown, 2021). The current work contributes to advancing a practice-oriented identity work perspective relating to the study and practice of managing leader identity in workplace settings.

Leader identity is defined by Miscenko et al. (2017) as the degree to which leaders view themselves as a leader. Leader identity has been further described as an identity (or subcomponent of one's identity) that individuals have relating to their role as a leader (Day et al., 2009). In this article, managing leader identity is defined as a process seeking to help leaders assess, prioritize, understand, integrate and affirm their leader - self-views and align them with actions that challenge them to optimally strengthen their leader identity for enhanced positive impact on desired outcomes.

Ferris et al. (2018) remind us that the topic of "the self" and related subject areas are pervasive in workplace settings. Organizational studies and applications relating to the self address such areas as positive leadership, self-control depletion and organizational-relational identification (Brown, 2021; Hannah et al., 2009; Koopman et al., 2016). The work relating to leader self-view systems and leader development across 
the lifespan are particularly relevant to managing leader identity (Liu et al., 2020). These leader-self views include leader self-identity, self-awareness, and self-efficacy and contribute to defining an individual's identity/self-concept as a leader (Day et al., 2009; Hannah et al., 2009). A leader's system of self-views influence such things as performance, motivational levels and self-control when responding to challenging situations (Kerns, 2013; Lord et al., 2011). These self-views are shaped and formed by varying experiences across one's lifespan (Day \& Dragoni, 2015; Liu et al., 2020).

The self-views of leaders that relate to leadership can be identified, organized and put into narrative form to help leaders clarify their identity as a leader. A leader's unique narrative can then be woven into a leadership story and communicated for high-impact to stakeholders as needed and appropriate (Bloom et al., 2020; Zheng et al., 2020). A leader's self-views, unique narrative and leadership story become key elements in the managing leader identity at work process.

Individual differences which are a core dimension of leadership further influence a leader's identity (Kerns 2015a; Kerns 2020a). Research also indicates that individual differences impact leadership emergence and effectiveness and that both dispositional and environmental influences substantially impact leader development (Antonakis et al., 2019; Zaccaro et al., 2018). These findings support the need for practical frameworks and tools to help leaders better understand, "who they are," as leaders in relationship to relevant individual difference making factors such as personality and core values (Kerns, 2017a; Kerns, 2017b; McLean et al., 2020). When working with C-level executives to help them assess and strengthen their leader identities, relevant individual difference making factors as well as impactful leader experiences across their lifespan are assessed and considered (Kerns 2015a; Kerns, 2018a). A unique leader resource profiling (ULRP) process is typically used along with other assessment methods to help leaders determine a set of core and complementary leader identity factors which become important elements for leaders in managing their identities at work (Kerns, 2020a). ${ }^{1}$

Leader development and leader identity are non-linear dynamic processes which unfold and are shaped over time (Day \& Liu, 2019; Day \& Sin, 2011; Miscenko et al., 2017; Riggio, 2011). During this developmental process exposure to varying situational contexts serve as opportunities for leaders to learn, grow and develop. Situational context is also a core leadership dimension which over time helps emerging as well seasoned leaders enhance their situational awareness (Kerns, 2015b). Leader self-awareness along with situational-awareness are competencies that enhance leader identity management. These two processes help leaders recognize what is going on around them as well as more closely notice their overt as well as covert reactions to the circumstances they encounter. (Leaders who measure high on the personality trait of self-monitoring, which is the capacity to adapt their behavior to external situational dynamics, may be less challenged than low self-monitors when reading and adjusting to situations (Park-Leduc et al., 2014). This dynamic interaction between a leader's propensity to self-monitor and situational circumstances underscores the notion that managing leader identity is a dynamic multifaceted process.)

The emerging fields of brain science, learning science and positive psychology as applied to organizations connect in practical ways with managing leader identity. In particular, the work surrounding brain neuroplasticity indicates that leader behavior can be changed by better understanding and managing habit formation (Eagleman, 2020; Harvey et al., 2021; O'Mara, 2018). My current work in helping leaders change specific identity related behaviors, for example, those associated with achieving aspirational goals, is offering promising results. Also, closely aligned with this work relating to habit formation, behavior change, and brain science is experiential learning. The extant literature indicates that challenging developmental experiences are important to leader development (Day et al., 2009). These findings encourage those involved in leader identity management work to engage leaders in challenging experiential learning activities that help leaders strengthen their leader identity and support them in making changes to optimize their positive impacts at work (Kerns, 2019; Passarelli \& Kolb, 2021).

Leadership, time and time perspectives are also in line with helping leaders manage their leader identity (Day \& Liu, 2019; Lord, 2019). In particular, the management of time perspectives is a key practice associated with enhancing well-being drawn from the field of positive psychology (Kerns, 2012; Kerns, 2018b). It is desirable for leaders to manage their leader identity using a balanced time perspective. A balanced time perspective means giving appropriate attention to one's past, present and future. In terms of 
managing leader identity, leaders can benefit by reviewing who they were, who they currently are and who they want to become. When helping leaders examine their leader identity across time, it is important to work toward having leaders develop an integrative picture of themselves as leaders who recognize the past, present and the future in a coherent and congruent way. This outcome helps strengthen their leader identity while helping to enhance their well-being as leaders. Typically, in my work with leaders it has proven valuable to have them develop and deliver a clear coherent leadership story that they find motivating and meaningful (Bloom et al., 2020). This is often an indicator of the strength of their leader identity. This process helps them discern the extent to which they have integrated their past, present and future time perspectives into a coherent and integrated leader identity. As learning and growth occur, some aspects of a leader's identity will likely evolve and may contribute to their positive impact on achieving desired outcomes (Shaughnessy \& Coats, 2019).

This article offers a practice-oriented framework for understanding and managing leader identity. The framework is supported by a management cycle which helps leaders apply the model. The framework's and cycle's application value, implications and some challenges in managing leader identity are presented. The framework is embedded within a comprehensive system of managerial leadership which I authored, continuously study and apply in diverse workplace settings with colleagues and practitioners over the past several decades with the goal of assisting leaders in achieving desired outcomes. ${ }^{2}$ The current article focuses on the practice of managing leader identity which is most closely associated with individual differences and situational context within the broader system. Effectively managing leader identity helps leaders better understand who they are as a leader and how they can draw upon their self-knowledge and uniqueness to optimize their impact across the different situations they face at work.

\section{LEADER IDENTITY MANAGEMENT}

Leader identity management is connected to the concept of the self and related topics as previously noted. In order for the leader identity management process to be relevant and useful, leaders' self-views need to include seeing themselves as leaders. The degree to which leaders view themselves as leaders also has implications for how an executive coach or other designated professional facilitator proceeds in helping leaders manage their identity as a leader. ${ }^{3}$ Emerging leaders without significant leadership experience may need additional time to work through their self-perceptions regarding leadership and its relationship to their leader identity (London \& Sherman, 2021). It has been my experience in coaching leaders through the leader identity management process that new arrivals to leadership positions do not necessarily have sufficient experience in proactively claiming or having others grant them leadership opportunities over their lifespan, which causes them to lack a clear set of leadership related self-views of themselves as leaders. (This concept of claiming and granting opportunities to lead, as formulated by DeRue \& Ashford (2010), has diagnostic relevance especially during the initial phase in the managing leader identity process.)

Leader identity management is a dynamic process wherein the strength of leaders' identities may vary over time and circumstances (Day \& Sin, 2011; Shaughnessy \& Coast, 2019). Changes in a leader's identity may stem from external events such as promotions or by engaging in professionally facilitated leader development activities designed to strengthen leader identity. My observations regarding the variability of a leader's identity across time and contexts are in line with others who have examined the robustness of leader identities over time and as leadership roles are executed (Ibarra, 1999; Miscenko et al., 2017). Also, leader identity management involves helping leaders understand and manage the intrapersonal aspects as well as the interpersonal components of their leader identity (Yip et al., 2020).

The identity of leaders develops along various dimensions, strength, integration, meaning, and levels (personal, relational and collective) which come together to create a leader identity narrative (Clapp-Smith et al., 2019; Hammond et al., 2017). It has been my experience that leaders have a unique leadership related narrative that can help them clarify and strengthen their leader identity provided it is clear, coherent, and credible. Also, leader identity is further strengthened when the narrative is motivating and meaningful to the leader. The leader identity management process helps leaders develop, document, and articulate their leadership narrative as a story which often becomes a key element of their leader identity (Bloom et al., 
2020; Ibarra \& Barbulescu, 2010; McAdams, 2013). A leader's unique narrative and the development of a story helps leaders integrate key life experiences, events and people influences into their leader identity. It also helps in facilitating leaders in identifying their core and complementary leader identity factors which are subsets of their overall leader identity.

Further, there is increasing interest in connecting one's understanding of leader identity with the process of developing leadership competencies (Kragt \& Day, 2020). Also, leader identity is receiving increased prominence and importance in the study of leader development and effectiveness in the extant literature (Day \& Dragoni, 2015; Epitropaki et al., 2017). It is being suggested that identity work is foundational to effective leadership development (Clapp-Smith, et al., 2019) which aligns with the focus of this article. Indeed, practice-oriented approaches to managing leader identity can likely add value to the efforts of practitioners, teachers and applied researchers who are interested in advancing and enhancing the role that leader identity plays in leader development and effectiveness.

Based on a review of the literature and decades of study and practice, I support the notion that identityoriented approaches to leader development can strengthen leader identity and positively influence the impact leaders have on desired outcomes. The current article is intended to offer a practice-oriented framework and management cycle for managerial leaders to use to better understand and manage leader identity.

\section{FRAMEWORK AND IDENTITY MANAGEMENT CYCLE}

In developing frameworks and tools to strengthen leader identities and enhance their impacts on desired organizational outcomes, I have along with colleagues utilize the following set of criteria (Kerns \& Ko, 2014). The framework and tools need to:

- Have face validity for practitioners

- Add value to an organization

- Be relevant to practitioners' daily work

- Be evidence-based in practice and/or applied research

- Be practical to implement in an organizational operating environment

- Be coachable/teachable

With the above criteria as guideposts, I have developed a practice-oriented identity management framework which focuses on two areas relating to managing leader identity. This framework has been applied in many settings including work organizations, executive education classrooms, and applied research projects. The model is practitioner friendly and draws from and is conceptually connected to the relevant literature (including the work previously noted) relating to the study of organizational and leader identity (Barends \& Rousseau, 2018).

Figure 1 displays the two key dimensions related to managing leader identity, i.e., leader identity strength and leader impact. These two dimensions are found in the matrix and briefly reviewed. 


\section{FIGURE 1}

\section{LEADER IDENTITY STRENGTH - IMPACT MATRIX FRAMEWORK @}

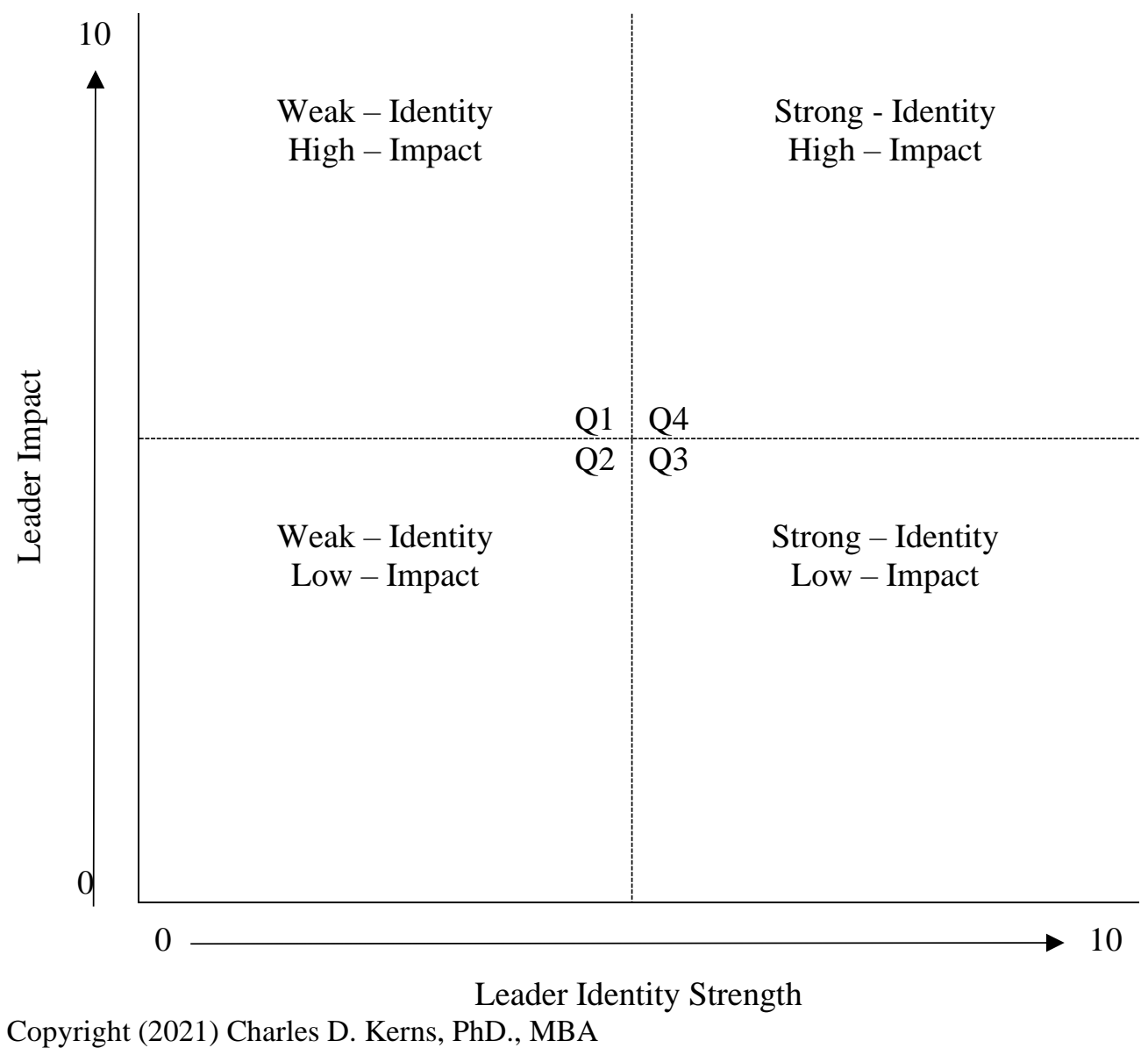

\section{Leader Identity Strength Dimension}

Individual leaders are asked to rate and plot their perception of their leader identity strength on the horizontal axis as depicted in Figure 1. (Ratings can range from a low of zero to a high of 10.)

Leaders are also asked to consider the following five strategic questions when rating their leader identity strength:

1. How clear is it?

2. How credible is it?

3. How coherent are the core elements?

4. How captivating is it?

5. How connected is it to transcendent meaning?

These five questions reflect some of the ways that leader identity has been characterized in the extant literature (Day \& Harrison, 2007; Hammond et al., 2017). In my work with leaders as an executive coach/advisor, I will often use the phrase, "the 5 C's of leader identity strength." The "5 C's" questions become a mnemonic device that helps one remember these five key characteristics of leader identity strength. I also will typically ask a leader as part of orienting to the leader identity management process, "To what extent is your leader identity clear, credible, coherent, captivating and connected to you in some transcendent meaningful way?" 


\section{Leader Impact Dimension}

Individual leaders are also asked to rate how effective they are in using the core elements of their leader identity to positively impact desired outcomes relating to performance, well-being and well-doing. As in rating their leader identity strength, individual leaders are asked to plot (along the vertical axis found in Figure 1) how effective they are in positively impacting desired outcomes from 0 to 10 with 10 being the highest rating.

As shown in Figure 1, the dimensions of leader identity strength and leader impact interact to form four quadrants. This matrix provides a springboard for conversations regarding the ratings of a leader on each dimension. In practice, it has proven useful in helping leaders identify which of the " $5 \mathrm{C}$ 's" most likely represent areas for them to consider strengthening or perhaps exploring further. Likewise, leaders' ratings of their impact provides opportunities to discuss numerous important topics such as the clarity of their desired outcomes, and the connections between their identity strength rating including the " $5 \mathrm{C}$ 's" and their perceptions of their impact with key stakeholders across specific challenging situations.

While there is some interest in the extant literature for examining the impacts that leader identities have on desired outcomes, this area, for the most part, remains an opportunity for further consideration (Kragt \& Day, 2020). It should be noted that this framework is used with leaders to facilitate conversations regarding the strength of their leader identities and the impact that their identities are having directly or indirectly in such areas as performance, well-being and well-doing. It is not utilized as a psychometrically validated measurement instrument. Rather, it is a facilitation tool for valued-added conversations with individual managerial leaders regarding their leader identity strength and its relationship to their leader impact on desired outcomes in specific situational contexts.

Significant opportunities exist for practitioners, researchers and teachers to draw upon the known and evolving knowledge relating to managing leader identity in workplace settings. The framework offered here extends this knowledge by building upon observations and experiences gathered by me and colleagues while working with a broad range of managerial leaders across industries. Based on fieldwork, applied research and consulting that addresses the areas noted earlier coupled with reviews of relevant literature, I have made the following observations about managing leader identity:

- Practitioners appear to find the management of their identities as leaders relevant and consequential.

- It seems clear that understanding and managing one's identity as a leader can be challenging especially for emerging leaders.

- Less attention has been paid to the connection of leader identity to key outcomes than has been afforded the examination of leader identity as a concept separate and apart from leader impact. There is, however, evidence that this is changing (Kragt \& Day, 2020).

- A substantial challenge for managerial leaders when considering managing leader identity is prioritizing and focusing on the most important and actionable elements that define the concept of core leader identity. Facilitating leaders in developing and documenting their Unique Leader Resource Profile (ULRP) has been especially valuable in helping to identify and prioritize the elements which define their core leader identity (Kerns, 2020a).

- Leader identity is a multifaceted concept and connects with many different topics and areas making it additionally challenging for practitioners to apply and manage in workplace settings (Day \& Harrison, 2007; Hannah et al., 2009; Shaughnessy \& Coats, 2019).

- Leader identity management is closely linked with individual differences and situational context as studied in the field of leadership (Kerns, 2015a; Kerns, 2015b).

- Leadership development and human development are connected to the formation and management of leader identities (Day et al., 2009; Liu et al., 2020; Miscenko et al., 2017; Riggio, 2011).

- Leader identities cut across different levels that include individual, relational, and collective (Day \& Harrison, 2007; DeRue \& Ashford, 2010). This challenges leaders to continuously 
learn, grow and adapt to change as they strive to successfully perform in workplace settings. Transitioning from one level to another presents opportunities as well as challenges.

- The study of the content of leader self-views, especially relating to their positive or negative valence as well as how the content is organized and self-assessed, is integral to managing leader identity (Hannah et al., 2009). Importantly, leaders construct narratives when recalling significantly impactful situations. These personalized recollections retrieved from their autobiographical memories often become important elements of their leader identity and leadership story (Bloom, 2020; Habermas \& Kober, 2015; Kerns, 2018a; McLean et al., 2020).

- Having leaders identify, prioritize and focus on a set of core and complementary leader identity factors, as part of their broader unique leader profile, has brought additional clarity and impact to the process of managing leader identity (Kerns, 2020a; Kerns, 2021a).

- Having leaders view their core leader identity in a broader context by considering relevant leader identity spheres of influence which impact them offers leaders a more strategic context from which to view their core leader identity (Kerns, 2015b). These relevant leader core identity spheres of influence include areas such as a leader's ULRP, categorical group affiliations and transcendent motivations (Kerns, 2021b).

- Digital technologies hold promise in helping provide innovative ways to assess and measure changes in leader identities over time in applied settings (Bettis et al., 2021).

- The study and practice of managing leader identity is ripe for interdisciplinary collaboration across diverse fields of study such as neurobiology, brain, learning and behavioral sciences (Bar, 2021; Harvey et al., 2021; Keeling et al., 2021; Zak, 2018).

Based on the above observations and studying the topic of leader identity and leadership, a set of practices has emerged that can help a managerial leader better understand and manage leader identity. These practices are sequentially represented in the four phases of the leader identity management cycle found in Figure 2.

Practitioners are in need of frameworks and tools that align with a set of useful criteria (such as those previously noted) to help them enhance their effectiveness. The leader identity management cycle as depicted in Figure 2 helps operationalize the definition of managing leader identity and the related process in a general way. I have found this process to be useful in my consulting, teaching and applied research in helping leaders better understand and manage their leader identity.

The leader identity strength - leader impact matrix helps in further focusing and operationalizing the leader identity management process by drawing leaders' attention to the strength of their leader identity and its impact on achieving desired outcomes. Taken together, the framework along with the management cycle offered here can add value to the process of helping leaders better understand how to manage their identities for positive impact in workplace settings.

The four components in the Leader Identity Management Cycle are presented in chronological order of the most basic provisions for managing leader identity. However, the components are inter-related and in practice dynamically interact. The discussion below describes the components and the interplay among them. 


\section{FIGURE 2 \\ LEADER IDENTITY MANAGEMENT CYCLE @}

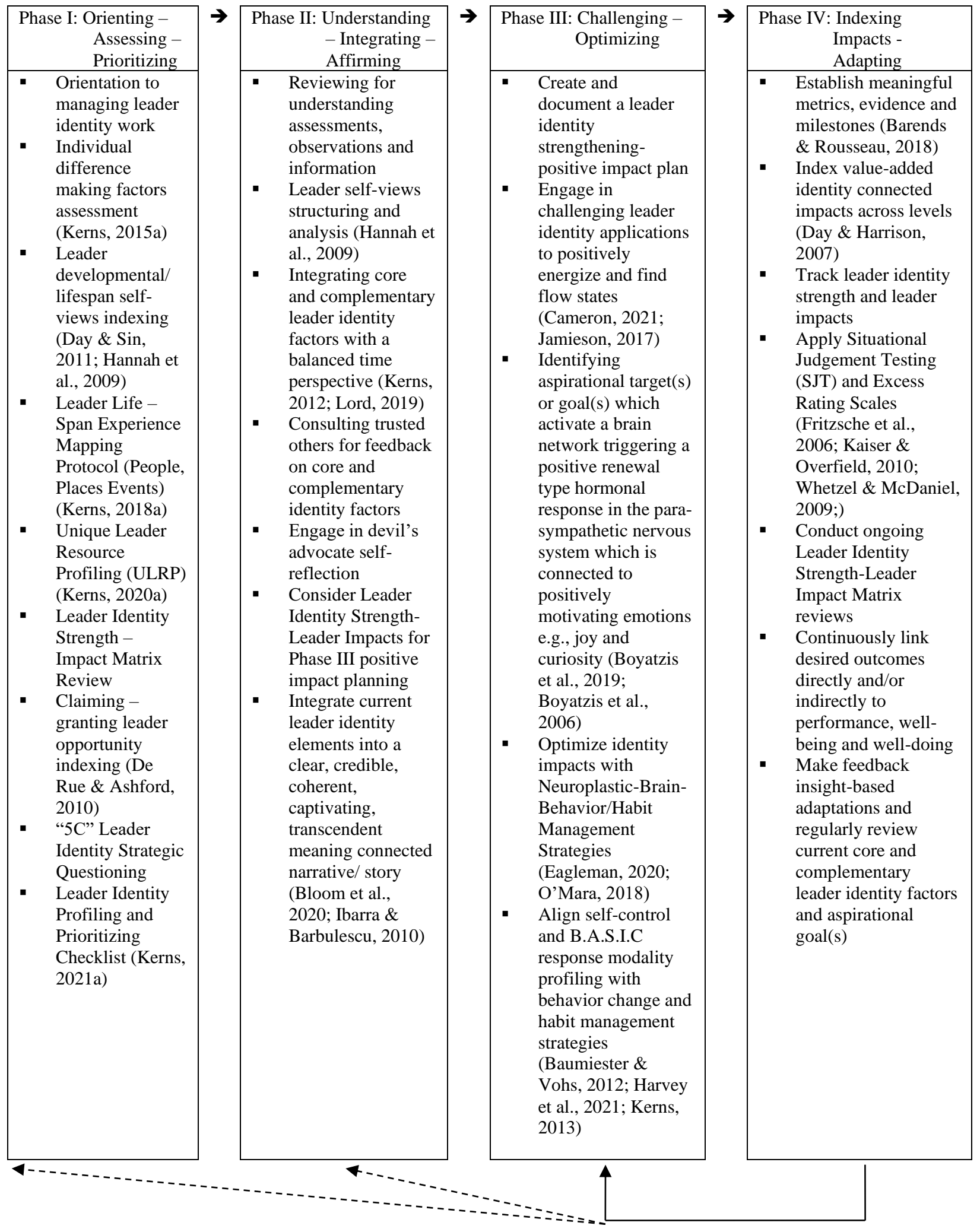

(c) Copyright (2021) Charles D. Kerns, Ph.D., MBA 


\section{Phase I: Orienting - Assessing - Prioritizing}

It is important during Phase I that leaders orient to some key concepts relating to leader identity. This includes helping leaders recognize the potential interaction between leader identity strength and leader impact as depicted in the matrix offered in Figure 1. This phase also involves orienting leaders to the notion that leader identity management is a dynamic multifaceted process, a process that when effectively managed can likely positively impact the performance, well-being and well-doing of leaders and those they serve. During Phase I, leaders are also made aware of the important role that core and complementary leader identity factors play in helping to shape leader identity and potentially be leveraged to optimize a leader's positive impact. It is also in this phase that the core leader identity factors and complementary factors are assessed and prioritized as subsets of a broader index of identity elements. Also, the importance of defining leader identity in a clear, coherent, and credible way is underscored while emphasizing that a leader's identity is further strengthened when it is viewed as captivating and connected to transcendent meaning for the leader.

During this phase the leader also considers other assessments which are intended to help identify and prioritize key individual differences making factors such as relevant lifespan experiences, leader claiming and granting opportunities (DeRue \& Ashford, 2010) and growth versus fixed mindsets (Dweck \& Molden, 2017). In addition, the leader identity profiling and prioritizing checklist and the process of developing and documenting a leader's unique leader resource profile (ULRP) are used as assessment tools (Kerns, 2020a; Kerns, 2021a). This phase offers leaders the opportunity to gain insight and self-knowledge into how their unique individual differences may connect with their self-views relating to leadership that they have acquired over their lifetime. A key objective for this phase is having leaders recognize the importance of leader identity strength and its potential impact on desired outcomes across organizational levels (Day \& Harrison, 2007) and diverse stakeholders.

\section{Phase II: Understanding - Integrating - Affirming}

After the leader is oriented to the basic concepts and processes underlying managing leader identity, it is important that these areas as well as relevant assessments be understood, integrated and affirmed. Reviewing these concepts and assessments through a holistic lens helps leaders gain a better understanding of who they are in relationship to managing their identity for increased positive impact. This often involves leaders further reviewing and reflecting more closely on how their five to ten core leader identity factors gleaned from completing assessments in Phase I are integrated into their self -views of who they are as a leader. As part of this review process, leaders frequently engage in devil's advocate self-reflection wherein they challenge the validity of some of their relevant leader self-views to more fully understand how these views may be impacting desired outcomes. Further, it is helpful for leaders to seek feedback from others regarding the congruence between their self- perceptions and those of others. This process of seeking feedback, especially from trusted others, can help provide credible support of a leader's identity by affirming that their self-views are congruent with those of others. Conversely, this feedback process may indicate discrepancies between the leader's self-views and those of others regarding who they are as a leader.

In my work with executives, some leaders rate their identity strength as strong and their positive impact on desired outcomes as high while others see their identity strength as either weak or strong but rate these leaders as having low positive impact when it comes to positively influencing desired outcomes. In many cases these discrepant views reflect a lack of self-awareness and/or situational awareness (Klimoski \& Hu, 2021). These situations, however, create opportunities for leaders to reflect on these disparate views and consider challenging themselves to take actions in Phase III to help optimize their impact on desired outcomes as part of their leader identity strengthening-positive impact plan. These actions may include leaders selectively modifying some of their self-views and concurrently making specific changes in their leader behavior. They may also update their leadership story to reflect their self-view and leader behavior change plans as part of their impending work in Phase III. 


\section{Phase III: Challenging - Optimizing}

After integrating, understanding and affirming and/or pointing out incongruencies in a leader's identity narrative, a number of useful things can be done to challenge and help leaders optimize their leader identities for enhanced impact. For example, leaders can be given core identity challenges to positively energize them and encourage their engagement in flow states (Cameron, 2021; Jamison, 2017). These efforts are typically embedded in an individualized identity - positive impact plan. Plans also include the identification of aspirational identity change targets or goals which trigger positive motivating areas in the brain (Boyatzis et al., 2019; Boyatzis et al., 2006). Closely associated with these actions are activities designed to optimize identity impacts through the use of evidenced based behavior/habit management strategies which capitalize and draw upon brain science especially relating to brain neuroplasticity and the opportunities for neurobiological rewiring (Eagleman, 2020; Kerns, 2013; O’Mara, 2018).

Self-control/self-regulation strategies are also introduced during Phase III that help inoculate leaders against setbacks they may face in implementing behavioral change/habit management programs. These strategies help leaders specifically manage their habitual responses to known triggers or situational cues that tempt them to stray from their personalized leader identity strengthening - positive impact plans. These self-control/self-regulation responses can be challenging for leaders to execute but become points of satisfaction when successfully completed. Leaders' satisfaction is especially piqued when they connect their self-control efforts with optimizing their leader identity for positive impact on desired outcomes. The impacts of leader self- control /self-regulation strategies are regularly tracked and indexed as part of Phase IV.

\section{Phase IV: Indexing Impacts - Adapting}

Establishing meaningful metrics and milestones is a key element in Phase IV of the leader identity management cycle. Indexing value-added identity connected impacts across selective organizational and relational levels is important in assessing leader impact. During this phase, the Leader Identity Strength Impact Matrix is regularly used to track a leader's identity strength as one potential indicator of their multilevel impact(s). Also, impacts that directly or indirectly influence key stakeholders' performance, wellbeing and well-doing are regularly reviewed as part of Phase IV. Making ongoing adaptations and regular adjustments to the leaders' action plans designed to optimize their positive impact on desired outcomes is integral. Excess rating scales are useful in helping leaders measure their effectiveness in adapting their actions to the developmentally challenging situations that they choose to engage in as part of their plan to optimize the positive impacts that their specific leader identity related behaviors are having on desired outcomes (Kaiser \& Overfield, 2010). More specifically these rating scales are helpful in indicating which behaviors associated with a leader's core identity factors need to be displayed less or more frequently in specific situational contexts. In turn, situational judgement testing helps leaders proactively practice potential behavioral responses to challenging situations that they anticipate encountering (Fritzsche et al., 2006; Whetzel \& McDaniel, 2009). Taken together, excess rating scales help leaders target behavioral areas in need of developmental attention and situational judgement tests offer leaders the opportunity to practice responding to these impending developmentally challenging situations.

\section{APPLICATION VALUE AND IMPLICATIONS}

Work relating to managing leader identity has application value and implications for practitioners, researchers and teachers. All three groups are contributors to helping emerging leaders as well as practicing leaders learn, grow, and develop. These groups can help shape and influence the formation of positive leader identities at work. Practitioners especially can benefit from having practical frameworks and tools to help them better understand and manage their leader identity. A discussion of the application value and implications of the current work across practice, research and teaching domains follows. 


\section{Practice Domain}

Using the leader identity strength-impact matrix and the leader core identity management cycle as reference points may further facilitate discussion on ways to help managerial leaders more fully understand and manage their identities as leaders for positive impact. This framework and management cycle has served as a practical springboard for productive conversations concerning the dynamic interplay and relationship between leader identity and its role in impacting desired outcomes in workplace settings. From these conversations, insightful patterns have emerged about leaders' self-views and how they relate to identity strength and leader impact in accomplishing desired outcomes.

An especially useful way to apply the framework has been to present the leader identity strength-impact matrix to executives when they are looking to explore cues relating to their behavior and its impact on desired outcomes. In this approach leaders are asked to rate their perceptions of the strength of their leader identity as they consider the " $5 \mathrm{C}$ " leader identity strategic questions. This application typically helps leaders recognize key elements associated with their leader identity which may be impacting their effectiveness at achieving certain desired outcomes. It has been especially useful in helping leaders more clearly see the importance of comparing their self-views regarding the strength of their leader identity with others' perceptions. When self-views are congruent with others' perceptions, there seems to be a strengthening of a leader's identity. In contrast, when there are incongruencies between a leader's identity and the perceptions of others, the leader's credibility is weakened which may, in turn, lessen their positive impacts on people and situations.

More broadly, feedback from others has stimulated leaders to further reflect on the " $5 \mathrm{C}$ " leader identity strategic questions. This process has not only identified credibility gaps between the self-perceptions of leaders and others but also has provided valuable information regarding leader identity clarity and coherence. This information has been used by leaders to help them better connect their core identity elements to their impacts. It seems that this process helps leaders increase their self and situational awareness in ways that positively impact desired results.

The five questions have also been used with organizational teams to help them better understand and manage the various leader identities found among their team members. This process seems to help teams become more cohesive and effective when working together to identify challenging issues and to effectively resolve them. During this process teams have been observed to increase their alignment and engagement around their purpose and goals while recognizing and optimizing their interdependencies. On numerous occasions the process of reviewing the five questions in relationship to the team's purpose and targeted key result areas has favorably impacted team commitment and cohesiveness while positively impacting the achievement of desired outcomes.

The framework and management cycle has also proven to be useful in helping leaders to formulate and tell their leadership story (Bloom, et al, 2020). Formulating and telling one's leadership story offers a method for leaders to help others get to know them better while helping the leaders more fully understand who they are as a leader. This process also helps leaders gain additional clarity and coherence in formulating the contents of their stories. Telling their story to others also helps boost their confidence in their leader identity narrative. An additional benefit from this process is the useful feedback that leaders obtain from others who listened to their story.

The above leader identity management application has also been adapted and applied with executive teams to help them enhance their working relationships and team performance. Team members are asked to identify their core leader identity factors and share them with the rest of the team as part of telling their leadership story to the other members of the team during a planned team development workshop. Workshop preparation includes each team member completing a leader identity strength-impact index worksheet to help in focusing on generating core leader identity factors. Drawing upon this pre-workshop activity each team member shares their core identity factors at the workshop. This application typically helps teams further recognize that there is a "me" in "team" and there is value in knowing how each member's core identity and their respective collective identities may be impacting their working relationships and team performance. This activity has proven to be a valuable source of feedback to individual team members as well as to the team as a collective when connections are made between leader identities and team 
effectiveness. Individual team members gain new insights regarding how their behavior can be seen as a process "gain" or "loss" when it comes to impacting team performance. This activity helps reinforce the notion that there is a "me" (or unique member individual differences) at play when engaging in teamwork. Team members become more aware of how unique individual differences attributable to each team member can impact team performance.

\section{Research Domain}

While this article is focused on practicing managerial leaders to help them better understand and manage leader identity, several areas seem to be primed for additional research. It would be of interest to further investigate how to assess leader identity especially in applied settings. Presently, research studying the assessment and measurement of leader identities especially relating to outcome measures is sparse. While the current identity strength-impact matrix provides a valuable resource for exploring leader identity and generating important self-reflections from leaders, it would also be helpful to have additional frameworks and tools to assist leaders in assessing their identities. There are opportunities to build upon the current work in this area (Epitropaki et al., 2017; Kragt \& Day, 2020; McLean et al., 2020). An emerging and cutting-edge area for further exploration is the use of digital technologies to assist in assessing as well as applying interventions in real-world settings that address leader identity strength and impacts, especially relating to leader self-regulation and its connection to managing leader identities (Bettis et al, 2021).

It seems important to investigate the relationship between approaches to leader identity management and organizational performance, well-being and well-doing. Given the extensive literature on the incidence of managerial ineffectiveness, incompetence or worse abuse (Kerns, 2021c; Örtenblad, 2021), it seems relevant and important to connect these streams of research. Applied researchers have an opportunity to help organizations and those interested in leader development to better understand how individual leader identity factors influence well-being, well-doing and performance. The relationship between specific leader identity factors or perhaps identity factor constellations or profiles and their connection to leadership efficacy would seem to be a wise avenue for future conceptual and empirical work (Hannah et al., 2009).

The nature of leader identity alignments across diverse stakeholders is important. It seems likely that the impact of a leader's identity varies across stakeholders and situational contexts (Kerns, 2015). Kempster et al. (2019) remind us of the importance of looking beyond shareholder value and being intentional when interacting with diverse stakeholders to enhance well-doing while building asset value. These considerations especially come into play when engaging in acquisition strategies, making strategic talent management decisions and managing organizational culture (Kerns, 2020b). Organizational leaders could benefit from a better understanding of how a leader's identity can be an asset or liability when it comes to forming and sustaining alignments and linkages within and outside organizational boundaries. This area seems ripe for future research.

Closely associated with the previously noted opportunity is the need to better understand how specific situational contexts interact with leader identity. This work would help extend prior work regarding personality-organizational fit (Bono et al., 2014). There is a dynamic "J.O.B triad" that could benefit from further investigation as it relates to leader identity management. More specifically, knowing how leader identity interacts with different jobs $(\mathrm{J})$, across varying operating environments $(\mathrm{O})$ and with diverse bosses (B) would seem to have important implications for talent management decisions. These decisions likely relate to recruiting, selection and on-boarding as well as in managing other aspects of performance.

Given an important aspect of leader identity is credibility, it seems relevant and important to explore this area further. A leader's credibility connects with the study of leader authenticity (Avolio \& Walumbwa, 2014). In the context of managing leader identity, leaders' identities are likely weakened when their selfviews are found to be consistently incongruent with those of others who work with them. It would be useful to have a better understanding of how leader identity including a leader's self-views impact potential variables that influence measures of leader effectiveness. The recent work of Kouzes and Posner (2021) regarding the characteristics that others look for in their leaders can likely inform future work surrounding managing leader identity, credibility and authenticity. For example, their research finds that for others to 
readily follow someone they must see that individual as trustworthy, capable, energetic and having a sense of direction.

Finally, studying managing leader identity also stimulates and encourages interdisciplinary collaboration. This practice area provides an opportunity for different fields of scientific inquiry and related professionals to come together around the important topic of managing leader identity for greater impact across diverse situational circumstances. Also, practitioners can link with applied researchers interested in helping advance the practice and study of managing leader identity across different settings. These collaborative efforts provide the opportunity to bring together important and varied perspectives such as neuroscience, learning science, behavioral science as well as other disciplines. The current approach also signals an opportunity for these diverse disciplines to examine the best ways to assess and to help leaders optimize their leader identity. These efforts may be beneficial, for example, in studying how neurobiological dispositions and existing neural pathways can be positively impacted by behavior-oriented strategies designed to help leaders change ineffective habitual responses to workplace triggers (Gardner, 2015; Gardner \& Lally, 2018; Harvey et al., 2021). The growing work relating to habit formation and management is currently being extensively explored and applied with executives in my advisory/executive coaching work and in related field studies.

\section{Teaching Domain}

The teaching of leadership could benefit from having practical frameworks and tools to offer emerging leaders as well as experienced leaders looking to enhance their effectiveness. I have imported some of the applications used in organizational settings into executive business classrooms when teaching frameworks and tools associated with better understanding and managing leader identity.

Experiential exercises, in particular, have been used to help business students better understand and apply the leader identity strength-impact matrix. One especially impactful activity involves having students rate and plot their current perception of their leader identity strength without first having the benefit of reviewing the " $5 \mathrm{C}$ " leader identity strategic questions. This round of ratings tends to be challenging for students to complete. When they are subsequently asked to rate their leader identity strength after having had time to review and reflect on the five strategic key questions, they typically seem to have more confidence in their self-ratings regardless of whether their ratings move up or down. This experiential activity offers many teaching moments and opportunities for learning. Students typically comment on how managing leader identity especially given its multidimensional nature is challenging. They also appreciate how the leader identity strength - leader impact matrix offers them a practical way to define their leader identity strength and reflect on its impact in influencing desired outcomes. Also, the five C's mnemonic device which represents the five-leader identity strategic questions is consistently seen as a practical tool that helps learners appreciate some of the challenges in understanding and managing one's identity strength as a leader.

Another activity that is relevant, applicable and impactful in facilitating learning relating to managing leader identity is having students engage in core identity factor spotting wherein they first write down five characteristics that they believe are reflective of their core identity as a leader. They are then asked to share their five characteristics with classmates. After listening to their fellow student's core identity factors, classmates are given an opportunity to affirm or otherwise comment on what they heard. This activity has proven to be a springboard for many rich exchanges and a practice field for enhancing behavioral observation skills as well as self-awareness. One consistent and yet initially unexpected outcome of this activity is the gratitude students express about the feedback they receive from fellow classmates. Typically, the feedback includes learning about additional positive attributes that are observed by their classmates. In many cases these additional positive attributes help not only to strengthen fellow students' identities as leaders but also provide additional confidence for students in believing in how they project their leader identity to others and who they are as a leader.

One of the most impactful ways to bring the framework and management cycle alive for students is to have successful executives present the growth and development of their leader identities over their lifespan. This activity especially helps demonstrate how identity development mirrors human development and is a 
process that unfolds over time. It is especially powerful when executives disclose how their leader identities developed and changed over time. This activity underscores many key takeaways regarding managing leader identity. It highlights how leader identity development is not a linear process. It also shines additional light on the importance of being a life-long learner and shows students that leader development by its nature entails learning, growth, and resilience (Day et al., 2009; Liu et al., 2020). It also reinforces the notion that knowing oneself as a leader connects with career success as exemplified by the leaders who share their developmental journeys which reveal how their leader identities were shaped, formed and optimized over time.

\section{SOME CHALLENGING ISSUES}

Efforts in helping to advance the understanding and practice of managing leader identity for practitioners presents some challenging issues. There is a need to have practical and user-friendly assessment methods for managerial leaders to identify, prioritize, affirm as well as manage their leader identity to optimize desired outcomes. In addition to being professionally designed, developed and psychometrically sound, these tools need to address the management of leader identity in a way that has face validity for business practitioners. In this vein, there is a need to develop more innovative, integrative and holistic approaches to developing and assessing leader identity factors. These efforts need to consider such areas as developmental influences, dispositional factors, individual differences and perhaps other relevant and impactful elements that may contribute to leaders optimizing their unique pattern of core leader identity factors. This work needs to recognize that developing and managing one's leader identity evolves over one's career and lifetime and is an ongoing developmental process not a singular event (Day \& Liu, 2019; Shaughnessy \& Coats, 2019).

Closely associated with the assessment challenge is the need to recognize time and situational context as vital variables in the development and management of leader identity (Lord, 2019). In particular, effectively developing and managing leader identity requires an understanding and appreciation of the need for a balanced time perspective across diverse and often challenging circumstances. With a balanced time perspective, leaders come to recognize the importance of learning from the past, focusing on what is important and what they can influence in the present while wisely looking into the future (Boniwell, 2009; Kerns, 2012).

Practitioners and those supporting their development are challenged to consider and integrate time perspectives and situational circumstances into the process of managing leader identity. Connecting leadership experience to situational context and time perspectives provides a challenging opportunity for practitioners, applied researchers and teachers of leadership to advance our understanding of these two areas as they relate to managing leader identity. I have found the use of situational judgment testing (Whetzel \& McDaniel, 2009) to be useful in helping leaders optimize the positive impact of their identity in current challenging situations as well as in anticipating how to respond to future challenges.

To address the paucity of evidence-based frameworks and tools for practitioners to review and utilize when addressing the management of leader identity, it would be useful and beneficial to challenge practice minded applied researchers to explore additional approaches to help leaders effectively manage their leader identity. In addition to the current practice-oriented framework and management cycle, applied researchers and/or evidence-based oriented practitioners are challenged to develop additional programs to help managerial leaders understand, manage and optimize their leader identity. This work would be especially beneficial if these approaches consider integrating practices into practical and coherent processes (Barends \& Rousseau, 2018).

Practitioners are challenged to link with applied researchers interested in helping advance the practice and study of optimizing leader identity across different operating environments. These collaborative efforts provide the opportunity to bring together important and varied perspectives found in the brain, learning, and behavioral sciences as well as other disciplines. These interdisciplinary efforts can help examine the best ways to assess and manage leader identity in applied settings. The current work, for example, investigating how digital technologies can be applied in the assessment and management of emotional 
regulation has application value in the study and practice of managing leader identity (Bettis, et al, 2021). Leader self-control coupled with self and situational-awareness are important competencies to better understand as they relate to managing and optimizing leader identity (Johnson et al., 2018; Kerns, 2015b). Also, the work connecting habit formation and management with neuroplasticity (or brain plasticity) is emerging and holds promise for informing the study and practice of leader identity management (Harvey et al., 2021; Keeling et al., 2021; O'Mara, 2018). My current work in applied settings is yielding useful results when adapting and applying brain coaching strategies in helping leaders more effectively manage their identities to positively impact desired outcomes (Boyatzis et al., 2006; Boyatzis et al., 2019).

Leader identity assessment and management has practical utility for practitioners when they are working with teams. Practitioners are challenged to integrate the concept that there is a "me" in team when working with teams and managing leader identity. It has been my experience that team functioning is influenced by leader identity. For example, some individuals do not see themselves as a "leader" unless they have a formal title that signifies they are in a leadership role. This self-view seems especially prevalent among emerging leaders and can weaken their leader identity strength and impact when working in teams. Beyond this circumstance, core leader identity factors can influence team performance positively or negatively. Practitioners are challenged to understand their self-views regarding teams, team development and teamwork. They also need to be aware of how other team members view teamwork. This challenge is offered, in part, to counter the often used phrase that there is no "I" in team but there certainly is a "me" in team. In the context of managing leader identity, it is important to recognize how an individual team member's identity may influence team functioning and outcomes.

Finally, managerial leaders are challenged to consider and work towards integrating attributes that are associated with positively energizing leaders as part of their developmental identity work relating to strengthening their leader identity for positive impact. There is a growing practitioner-oriented evidenced based literature that supports the benefits of positively energizing leadership (Cameron, 2021). Leaders who behave in positively energizing ways promote virtuous behavior/well-doing, enhance well-being and contribute to building flourishing relationships which strengthen organizational capital (Cameron \& Winn, 2012; Heaphy \& Dutton, 2008; Spreitzer et al., 2021; Kerns, 2018b; Zak, 2018). Challenging managerial leaders to consider integrating attributes of positively energizing leaders into their leader identity would seem to be a value-added developmental goal, a goal that would likely yield laudable returns for them, their people and their overall organization.

Addressing these challenges will likely enhance our understanding and knowledge of ways to assess and manage leader identity to achieve desired outcomes. As more focused attention is given to this practice area, additional challenges for practitioners, applied researchers and teachers will be offered. All of these efforts will help in moving this important topic forward to the benefit of leaders and those they serve.

\section{SUMMARY STATEMENT}

Managerial leaders and those interested in helping leaders optimize their performance, well-being and well-doing can benefit by having practical approaches that help them develop and manage their leader identity. Leaders who possess strong and positively impactful identities are more likely to make value added contributions to those they serve. As this work is carried forward, there will be a need for useful assessment tools and additional frameworks to help guide practitioners as they seek to strengthen their identities as leaders to achieve desired results. These efforts can benefit from collaborative interdisciplinary work to help shed additional light on ways to help practitioners better understand and manage leader identity. Having leaders make value added contributions as a result of strengthening their positive leader identities for increased impact will likely pay substantial dividends for stakeholders. Their individual efforts and those of others who help them optimize their identity for the common good is a laudable endeavor. 


\section{ENDNOTES}

1. To enhance the relevance, application value and impact for practitioners seeking to manage their leader identity at work, a number of professionally designed frameworks and tools are offered as part of a systematic identity management process. A pivotal part of this process is helping leaders assess prioritize, understand, integrate and subsequently affirm a unique set of core and complementary leader identity factors. These factors become an integral part of an ongoing leader identity strengthening-positive impact management planning process. This planning process is intended to challenge leaders to act in ways that optimize their identities as leaders including using their core identity factors to positively impact desired outcomes. Further, the complementary identity factors are thoughtfully aligned with a leader's core identity factors when situationally relevant and appropriate to further help a leader positively impact desired results. The identification and management of a leader's core and complementary identity factors is an ongoing dynamic developmental process which recognizes and reflects a leader's continuous learning, growth and development as a leader. This work is embedded in the leader identity management cycle found in Figure 2 in the current article.

2. This system of managerial leadership strives to provide practitioners, applied researchers and teachers with an integrated holistic approach to viewing and understanding leadership. The system includes bringing together several streams of leadership study and research that been offered over the past century. Concurrently, the management of leaders' identities at work which is the focus of the current article can help advance the practice, study and teaching of leadership. Over the years, I have extensively studied and integrated three foundational strategic optimal outcomes (i.e., performance, well-being and well-doing) into this managerial leadership system. Specifications of "desired outcomes" by leaders and their organizations as referenced in the current article are intended to directly and/or indirectly link with these three foundational strategic optimal outcomes across diverse organizational settings. It is, however, beyond the scope of the current presentation to review and discuss the other system dimensions and related practices.

3. The managing leader identity at work approach offered here can be applied by managerial leaders in a selfdirected mode or it can be facilitated by an external leader development professional. Typically, leaders initially engage in a coach the coach program with a professional facilitator before directly applying this practice-oriented approach with their people.

\section{REFERENCES}

Antonakis, J., Simonton, D.K., \& Wai, J. (2019). Intelligence and leadership. In M.D. Mumford \& C.A. Higgs (Eds.), Leader thinking skills (pp. 14-45). New York, NY: Routledge.

Avolio, B.J., \& Walumbwa, F.O. (2014). Authentic leadership theory, research and practice: Steps taken and steps that remain. In D.V. Day (Ed.), The oxford handbook of leadership and organizations (pp. 331-356). New York, NY: Oxford University Press.

Bar, M. (2021). From objects to unified minds. Current Practices in Psychological Science, 30(2), 129137.

Barends, E., \& Rousseau, D.M. (2018). Evidence-based management: How to use evidence to make better organizational decisions. New York, NY: Kogan Page.

Baumeister, R.F., \& Vohs, K.D. (2012). Self-regulation and the executive function of the self. In M.R. Leary \& J.P. Tangney (Eds.), Handbook of self and identity (2nd ed., pp. 180-197). New York, NY: Guilford Press.

Bettis, A.H., Burke, J.N., \& Liu, R.T. (2021). Digital technologies for emotion-regulation assessment and intervention: A conceptual review. Clinical Psychological Science. https://doi.org/10.1177/21677026211011982.

Bloom, M., Colbert, A.E., \& Nielsen, J.D. (2020). Stories of calling: How called professionals construct narrative identities. Administrative Science Quarterly, 66(2), 298-338. https://doi.org/10.1177/0001839220949502

Boniwell, I. (2009). Perspectives on time. In S.J. Lopez \& C.R. Snyder (Eds.), Oxford handbook of positive psychology (2nd Ed., pp. 295-302), New York, NY: Oxford University Press. 
Bono, J.E., Shen, W., \& Yoon, D.J. (2014). Personality and leadership: Looking back, looking ahead. In D.V. Day (Ed.), The oxford handbook of leadership and organizations (pp. 199-220). New York, NY: Oxford University Press.

Boyatzis, R., Smith, M., \& Blaize, N. (2006). Developing sustainable leaders through coaching and compassion. Academy of Management: Learning \& Education, 5(1), 8-24.

Boyatzis, R., Smith, M., \& Van Oosten, E. (2019). Helping people change: Coaching with compassion for lifelong learning and growth (pp. 77-100). Boston, MA: Harvard Business Review Press.

Brown, A.D. (2021, February 24). Identities in and around organizations: Towards an identity work perspective. Human Relations. https://doi.org/10.1177/0018726721993910

Cameron, K.S. (2021). Positively energizing leadership: Virtuous actions and relationships that create high performance. Oakland, CA: Berrett-Koehler Publishers.

Cameron, K.S., \& Winn, B. (2012). Virtuousness in organizations. In K.S. Cameron \& G.M. Spreitzer (Eds.), The Oxford handbook of positive organizational scholarship (pp. 231-243). New York, NY: Oxford University Press.

Clapp-Smith, R., Hammond, M.M., Lester, G.V., \& Palanski, M. (2019). Promoting identity development in leadership education: A multi-domain approach to developing the whole leader. Journal of Management Education, 43(1), 10-34.

Day, D.V., \& Dragoni, I., (2015). Leadership development: An outcome-oriented review based on time and levels of analyses. Annual Review of Organizational Psychology and Organizational Behavior, 2(1), 133-156.

Day, D.V., \& Harrison, M.M. (2007). A multilevel, identity-based approach to leadership development. Science Direct, 17, 360-373.

Day, D.V., \& Liu, Z. (2019). What is wrong with leadership development and what might be done about it? In R.E. Riggio (Ed.), What's wrong with leadership? Improving leadership research and practice (pp. 226-240). New York, NY: Routledge.

Day, D.V., \& Sin, H. (2011). Longitudinal tests of an integrative model of leader development: Charting and understanding developmental trajectories. The Leadership Quarterly, 22(3), 545-560.

Day, D.V., Harrison, M.M., \& Halpin, S.M. (2009). An integrative approach to leader development: Connecting adult development, identity, and expertise. New York, NY: Routledge.

DeRue, D.S., \& Ashford, S.J. (2010). Who will lead and who will follow? A social process of leadership identity construction in organizations. Academy of Management Review, 35, 627-647.

Dweck, C.S., \& Molden, D.C. (2017). Mindsets: Their impact on competence motivation and acquisition. In A.J. Elliot, C.S. Dweck, \& D.S. Yeager (Eds.), Handbook of competence and motivation: Theory and application (2nd ed., pp. 135-154). New York, NY: Guilford Press.

Eagleman, D. (2020). Livewired: The inside story of the ever-changing brain. Toronto, Canada: Penguin Random House.

Epitropaki, O., Kark, R., Mainemelis, C., \& Lord, R.G. (2017). Leadership and followship identity processes: A multilevel review. Leadership Quarterly, 28, 104-129.

Ferris, L., Johnson, R.E., \& Sedikides, C. (Eds.). (2018). The self at work: Fundamental theory and research (pp. 1-12). New York, NY: Routledge.

Fritzsche, B.A., Stagl, K.C., Salas, E., \& Burke, C.S. (2006). Enhancing the design, delivery, and evaluation of scenario-based training: Can situational judgement tests contribute? In J.A. Weekly \& R.E. Ployhart (Eds.), Situational judgement tests: Theory, measurement and application (pp. 301-318). New York, NY: Psychology Press.

Gardner, B. (2015). A review and analysis of the use of "habit" in understanding, predicting and influencing health-related behaviour. Health Psychology Review, 9(3), 277-295.

Gardner, B., \& Lally, P. (2018). Modeling habit formation and its determinants. In B. Verplanken (Ed.), The psychology of habit: Theory, mechanisms, change and context (pp. 207-229). Springer.

Habermas, T., \& Kober, C. (2015). Autobiographical reasoning is constitutive for narrative identity: The role of the life story for personal continuity. In K.C. McLean \& M. Syed (Eds.), The oxford handbook of identity development (pp. 146-165). New York, NY: Oxford University Press. 
Hammond, M., Clapp-Smith, R., \& Palanski, M. (2017). Beyond (just) the workplace: A theory of leader development across multiple domains. Academy of Management Review, 42(3), 481-498.

Hannah, S.T., Woolfolk, R.L., \& Lord, R.G. (2009). Leader self-structure: A framework for positive leadership. Journal of Organizational Behavior, 30, 269-290.

Harvey, A.G., Callaway, C.A., Zieve, G.G., Gumport, N.B., \& Armstrong, C.C. (2021). Applying the science of habit formation to evidence-based psychological treatments for mental illness.

Perspectives on Psychological Science, pp. 1-18. https://doi.org/10.1177/1745691621995752

Heaphy, E., \& Dutton, J. (2008). Positive social interactions and the human body at work: Linking organizations and physiology. Academy of Management Review, 33, 137-162.

Ibarra, H. (1999). Provisional selves: Experimenting with image and identity in professional adaptation. Administrative Science Quarterly, 44(4), 764-791. https://doi.org/10.2307/2667055

Ibarra, H., \& Barbulescu, R. (2010). Identity as narrative: Prevalence, effectiveness, and consequences of narrative identity work in macro work role transitions. Academy of Management Review, 35(1), $135-154$.

Jamieson, J.P. (2017). Challenge and threat appraisals. In A.J. Elliot, C.S. Dweck, \& D.S. Yeager (Eds.), Handbook of competence and motivation: Theory and application (2nd ed., pp. 175-191). New York, NY: Guilford Press.

Johnson, R.E., Muraven, M., Donaldson, T.L., \& Lin, J. (2018). Self-control in work organizations. In L. Ferris, R.E. Johnson, \& C. Sedikides (Eds.), The self at work: Fundamental theory and research (pp. 119-144). New York: NY: Routledge.

Kaiser, R.B., \& Overfield, D.V. (2010). Assessing flexible leadership as a mastery of opposites. Consulting Psychology Journal: Practice and Research, 62, 105-118.

Keeling, R., Dickson, J.S., \& Avery, T. (2021). Biological bases for learning and development across the lifespan. In M. London (Ed.), The oxford handbook of lifelong learning (2nd ed., pp. 57-72). New York, NY: Oxford University Press.

Kempster, S., Maak, T., \& Parry, K. (Eds.). (2019). Good dividends: Responsible leadership of business purpose. New York, NY: Routledge.

Kerns, C.D. (2012). Profiling and managing time perspectives: A systematic approach. International Leadership Journal, 4(1), 20-40.

Kerns, C.D. (2013). Self-control at work: Managing "hot buttons". Graziadio Business Review, 16(3).

Kerns, C.D. (2015a). Individual differences: A core leadership dimension. International Leadership Journal, 7(1), 54-77.

Kerns, C.D. (2015b). Situational context: A core leadership dimension. Journal of Leadership, Accountability and Ethics, 12(1), 11-24.

Kerns, C.D. (2017a). Leader personality at work: A key individual difference domain. International Leadership Journal, 8(1), 86-112.

Kerns, C.D. (2017b). Managing leader core values at work: A practice-oriented approach. Journal of Leadership, Accountability and Ethics, 14(1), 11-21.

Kerns, C.D. (2018a). Leader life-span experience management: A practice-oriented approach. Journal of Applied Business and Economics, 20(8), 105-119.

Kerns, C.D. (2018b). Impacting well-being at work: A key managerial leader action role. Journal of Management Policy and Practice, 19(1), 73-91.

Kerns, C.D. (2019). Managing leader learning preferences at work: A practice-oriented approach. Journal of Leadership, Accountability and Ethics, 16(5), 10-27.

Kerns, C.D. (2020a). Optimizing leader uniqueness: A practice-oriented approach. Journal of Leadership, Accountability and Ethics, 17(6), 10-26.

Kerns, C.D. (2020b). Managing organizational culture: A practice-oriented framework. International Leadership Journal, 12(1), 77-101.

Kerns, C.D. (2021a). [Leader Identity Profiling and Prioritizing Checklist]. Unpublished raw data.

Kerns, C.D. (2021b). Leader identity development: A practice-oriented strategic context framework. [Manuscript in preparation]. Applied Behavioral Science, PGBS, Pepperdine University. 
Kerns, C.D. (2021c). Bad leaders: Some realities, reasons and remedies. In A. Örtenblad (Ed.), Debating bad leadership: Reasons and remedies (pp. 219-237). Palgrave Macmillan: Cham, Switzerland.

Kerns, C.D., \& Ko, K.H. (2014). Managerial leadership competencies: A practice-oriented action role framework. International Leadership Journal, 6(1), 82-99.

Klimoski, R., \& Hu, X. (2021). Improving self-awareness and self-interest. In M. London (Ed.), The oxford handbook of lifelong learning (2nd Ed., pp. 73-96). New York, NY: Oxford University Press.

Koopman, J., Lanaj, K., \& Scott, B.A. (2016). Integrating the bright and dark sides of OCB: A daily investigation of the benefits and costs of helping others. Academy of Management Journal, 59(2). DOI: $10.5465 / \mathrm{amj} .2014 .0262$

Kouzes, J.M., \& Posner, B.Z. (2021). Everyday people, extraordinary leadership (pp. 6-9). Hoboken, NJ: John Wiley \& Sons.

Kragt, E., \& Day, D.V. (2020). Predicting leadership competency development and promotion among high-potential executives: The role of leader identity. Frontiers in Psychology, 11, 1816.

Liu, Z., Venkatesh, S., Murphy, S.E., \& Riggio, R.E. (2020). Leader development across the lifespan: A dynamic experiences-grounded approach. Leadership Quarterly, N/A, [101382]. https://doi.org/10.1016/j.leaqua.2020.101382

London, M., \& Sherman, G.D. (2021). Transitions to leadership as foundation for continuous learning: Development of leadership style and identity. In M. London (Ed.), The oxford handbook of lifelong learning (2nd ed., pp. 611-632). New York, NY: Oxford University Press.

Lord, R.G. (2019). Leadership and the medium of time. In R.E. Riggio (Ed.), What's wrong with leadership? Improving leadership research and practice (pp. 150-172). New York, NY: Routledge.

Lord, R.G., Hannah, S.T., \& Jennings, P.I. (2011). A framework for understanding leadership and individual requisite complexity. Organizational Psychology Review, 1(2), 104-127.

McAdams, D.P. (2013). The psychological self as actor, agent and author. Perspectives on Psychological Science, 8(3), 272-295.

McLean, K.C., Syed, M., Pasupathi, M., Adler, J.M., Dunlop, W.L., Drustrup, D., Fivush, R., Graci, M.E., Lilgendahl, J.P., Lodi-Smith, J., McAdams, D.P., \& McCoy, T.P. (2020). The empirical structure of narrative identity: The initial big three. Journal of Personality and Social Psychology, 119(4), 920-944.

Miscenko, D., Guenter, H., \& Day, D.V. (2017). Am I a leader? Examining leader identity development over time. The Leadership Quarterly, 28, 605-620.

O'Mara, S. (2018). A brain for business - A brain for life: How insights from behavioural and brain science can change business and business practice for the better. Cham, Switzerland: Palgrave Macmillan.

Örtenblad, A. (2021). (Ed.), Debating bad leadership: Reasons and remedies. Palgrave Macmillan: Cham, Switzerland.

Parks-Leduc, L., Pattie, M.W., Pargas, F., \& Eliason, R.G. (2014). Self-monitoring as an aggregate construct: Relationships with personality and values. Personality and Individual Differences, 58, 3-8.

Passarelli, A.M., \& Kolb, D.A. (2021). The learning way: Learning from experience as the path to lifelong learning and development. In M. London (Ed.). The oxford handbook of lifelong learning (2nd ed., pp. 97-129). New York, NY: Oxford University Press.

Riggio, R.E. (2011). Motivational roots of leadership: A longitudinal study from childhood through adulthood. The Leadership Quarterly, 22(3), 510-519.

Shaughnessy, S.P., \& Coats, M.R. (2019). Leaders are complex: Expanding your understanding of leader identity. In R.E. Riggio (Ed.), What's wrong with leadership? Improving leadership research and practice (pp. 173-188). New York, NY: Routledge. 
Spreitzer, G., Bacevice, P., Hendricks, H., \& Garrett, P. (2021). Thriving in the new world of work: Implications for organizational community. Research in Organizational Change and Development, 6, 1-60. New York, NY: Emerald Insight.

Whetzel, D.L., \& McDaniel, M.A. (2009). Situational judgment tests: An overview of current research. Human Resource Management Review, 19(3), 188-202.

Yip, J., Trainor, L.L., Black, H., Soto-Torres, L., \& Reichard, R.J. (2020). Coaching new leaders: A relational process of integrating multiple identities. Academy of Management Learning \& Education, 19(4), 503-520.

Zaccaro, S.J., Green, J.P., Dubrow, S., \& Kolze, M. (2018). Leader individual differences, situational parameters, and leader outcomes: A comprehensive review and integration. The Leadership Quarterly, 29(1), 2-43.

Zak, P.J. (2018). The neuroscience of high-trust organizations. Consulting Psychology Journal: Practice and Research, 70(1), 45-58. https://doi.org/10.1037/cpb0000076

Zheng, W., Meister, A., \& Caza, B.B. (2020). The stories that make us: Leaders' origin stories and temporal identity work. Human Relations, 74(8), 1178-1210.

https://doi.org/10.1177/0018726720909864 